\title{
Use of sputum eosinophil counts to guide management in children with severe asthma
}

\author{
Louise Fleming, ${ }^{1,2}$ Nicola Wilson, ${ }^{2}$ Nicolas Regamey, ${ }^{3}$ Andrew Bush ${ }^{1,2}$
}

\begin{abstract}
See Editorial, p 191
- Additional figures are published online only. To view these files please visit the journal online (http://thorax.bmj. com/content/67/3.toc).

${ }^{1}$ National Heart and Lung Institute, Respiratory Paediatrics, Imperial College, London, UK

${ }^{2}$ Department of Respiratory Paediatrics, Royal Brompton Hospital, London, UK ${ }^{3}$ Division of Paediatric Respiratory Medicine, Department of Paediatrics, Inselspital and University of Bern, Switzerland
\end{abstract}

\section{Correspondence to} Dr Louise Fleming, Department of Respiratory Paediatrics, Royal Brompton Hospital, Sydney Street, London SW3 6NP, UK; I.fleming@imperial.ac.uk

Received 30 November 2010 Accepted 22 June 2011 Published Online First 8 August 2011

\begin{abstract}
Background Previous studies in adults with asthma incorporating the control of sputum eosinophils into management strategies have shown significant reductions in exacerbations. A study was undertaken to investigate whether this strategy would be successful in children with severe asthma.
\end{abstract}

Methods 55 children (7-17 years) with severe asthma were randomised to either a conventional symptombased management strategy or to an inflammationbased strategy (principally sputum eosinophils). Children were seen 3-monthly over a 1-year period.

Results The annual rate of total and major exacerbations (courses of oral corticosteroids) was non-significantly lower in the inflammatory management group compared with the symptom management group (3.6 vs 4.8, incident rate ratio (IRR) $0.75,95 \% \mathrm{Cl} 0.54$ to 1.04 , $p=0.082$; and 1.9 vs 2.7 IRR $0.73,95 \% \mathrm{Cl} 0.42$ to 1.28 , $p=0.274$ for total and major exacerbations, respectively). Significantly fewer subjects in the inflammatory management group experienced an exacerbation within 28 days of a study visit. There were small non-significant differences in measures of asthma control (symptom-free days and short-acting $\beta$ agonist use) favouring the inflammatory management group. There was no significant difference in the inhaled corticosteroid dose prescribed over the course of the study.

Conclusion Incorporating the control of sputum eosinophils into the management algorithm did not significantly reduce overall exacerbations or improve asthma control. Exacerbations were reduced in the short term, suggesting that more frequent measurements would be needed for a clinically useful effect and that controlling inflammation may have a role to play in subgroups of children with severe asthma.

\section{INTRODUCTION}

Asthma is a chronic inflammatory disorder characterised by airway hyper-responsiveness and variable airflow obstruction which manifest as combinations of wheeze, cough and breathlessness. Current guidelines recommend that treatment is increased until control is achieved. ${ }^{1-3}$ Control is defined in terms of self- or parent-reported symptoms and measurements of airway obstruction. However, each has its limitations: symptom reporting is subjective and lacks specificity and even children with severe asthma may have normal lung function. ${ }^{4}$ Despite the limitations of current asthma guidelines and conventional assessment tools, for the majority of patients with asthma

\section{Key messages}

What is the key question?

- Can sputum eosinophil counts be used to guide management decisions leading to a reduction in exacerbations in children with severe asthma?

\section{What is the bottom line?}

- Exacerbations did not vary significantly in those managed according to an inflammation-based strategy compared with a conventional symptom-based strategy.

\section{Why read on?}

- This is the first such study carried out in children with severe asthma and the results are different from those reported for previous adult studies using a similar strategy.

they are adequate to guide therapy and maintain control with occasional short-acting $\beta$ agonist (SABA) use and low-dose inhaled corticosteroids (ICS). However, there remain a small number of children who require high-dose ICS and add-on therapies. Once higher treatment thresholds have been passed, it becomes ever more important to make correct management decisions and inadequacies in the current knowledge may have the most serious consequences for patients with severe asthma. If treatment is inadequate, symptom control will be poor, there may be an increased risk of exacerbations and an impact on quality of life. ${ }^{5}$ However, any increases in treatment need to be balanced against the potential side effects of highdose ICS $^{6}$ and add-on therapies. ${ }^{7}$

The most striking limitation of current guidelines is that, although asthma is an inflammatory disorder and ICS, the mainstay of treatment, are aimed at reducing inflammation, no measures of inflammation are included in routine assessments. Furthermore, current assessment tools (clinical control and spirometry) relate poorly to underlying eosinophilic inflammation. ${ }^{8}$ The absence of sputum eosinophils has been shown to be a predictor for successful ICS dose reduction in children with asthma, ${ }^{9}$ and in adult studies sputum eosinophils have been shown to be the hallmark of steroidresponsive disease. ${ }^{10-12}$ Previous studies in adults which have incorporated the measurement and control of sputum eosinophils into management algorithms have demonstrated a reduction in exacerbations in those managed according to sputum eosinophil counts. ${ }^{13-15}$ We hypothesised 
that, if a similar strategy was used in children with severe asthma, this would lead to a reduction in exacerbations and improvement in asthma control.

\section{METHODS \\ Subjects}

Children with severe asthma diagnosed after detailed evaluation by a paediatric respiratory physician and requiring treatment at steps 4 or 5 of the British Thoracic Society/Scottish Intercollegiate Guidelines Network (BTS/SIGN) guidelines ${ }^{3}(\geq 500 \mu \mathrm{g}$ fluticasone propionate (FP) per day or equivalent $(\geq 800 \mu \mathrm{g}$ budesonide per day) plus a long-acting $\beta$ agonist plus a trial of leukotriene receptor antagonist) were recruited from the Paediatric Outpatient Clinic at the Royal Brompton Hospital, UK between December 2005 and September 2006. There was no requirement for the patients to have current symptoms because we felt that this level of treatment constituted a sufficient risk to justify enrolment in the study. Patients were excluded if they were currently prescribed an immunomodulatory steroidsparing agent (such as ciclosporin, methotrexate or azathioprine) or a continuous infusion of subcutaneous terbutaline, or had received intramuscular triamcinolone in the previous 3 months or had another significant chronic respiratory or medical condition. Atopy was assessed at enrolment and defined as at least one positive skin prick test to common aeroallergens (cat, dog, tree pollen, grass pollen and Aspergillus fumigatus) using standardised extracts (Alk-Abelló, Hørsholm, Denmark).

\section{Study design}

Eligible subjects were randomly allocated to the symptom management group or the inflammatory management group using random numbers generated by an independent statistician, stratified for maintenance oral corticosteroid (OCS) use. Neither the subjects and their parents nor the health professionals involved in their clinical care knew the randomisation group. All subjects were seen during four routine clinic visits every 3 months, at which time the study procedures outlined below were carried out. Subjects were reviewed 3 months after their final study visit to assess clinical status and spirometry only. The study plan is shown in figure 1 .

The study was approved by the Royal Brompton Hospital ethics committee, carers gave informed written consent and children gave age-appropriate assent. The study was registered with http://clinicaltrials.gov (NCT00262340).

\section{Symptom and inflammatory management algorithms}

In the symptom management group, treatment decisions were based on the number of major exacerbations (defined as those necessitating treatment with high-dose OCS (>20 mg/day) for $\geq 2$ days) in the preceding 3 months and SABA use (daytime and

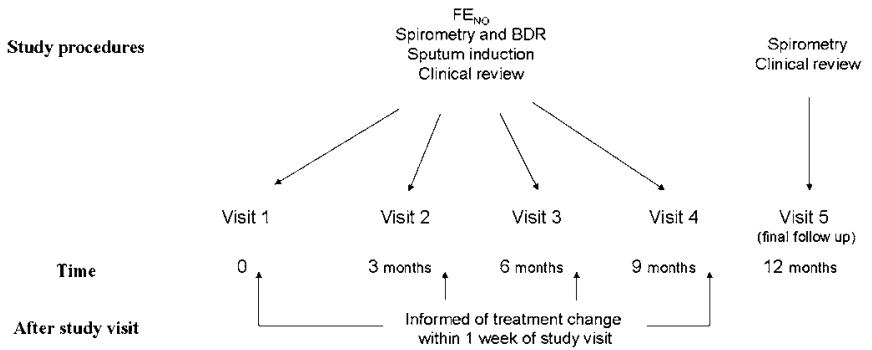

Figure 1 Study plan. BDR, bronchodilator reversibility; FE $_{\mathrm{NO}}$, exhaled nitric oxide. nocturnal) in the preceding 2 weeks (excluding routine use such as before exercise). The symptom-based algorithm was completed by a paediatrician blind to the subject's randomisation group. In the inflammatory management group, treatment decisions were based on the differential sputum eosinophil count (performed by an investigator blind to the identity, clinical status and randomisation group of the subject). If no sputum sample was produced the exhaled nitric oxide $\left(\mathrm{FE}_{\mathrm{NO}}\right)$ level was used instead. The treatment decisions are summarised in table 1 . The $2.5 \%$ level for sputum eosinophils was chosen as this is considered to be the upper limit of normal for sputum eosinophilia in children. ${ }^{16} 17$

\section{Treatment changes}

Doses of ICS were adjusted in increments of $250 \mu \mathrm{g}$ FP or equivalent per day. For those already prescribed maintenance OCS, doses were changed in increments of $5 \mathrm{mg}$ on alternate days. All subjects were contacted within 1 week of the study visit with treatment instructions. As a safety measure, subjects and their parents or the consultant in charge of their care could cap the ICS dose at $1000 \mu \mathrm{g} /$ day FP or equivalent.

\section{Study procedures}

Subjects were seen at the same time of day for each of their study visits.

$\mathrm{FE}_{\mathrm{NO}}$ was measured using an online single breath chemiluminescence analyser (NIOX, Aerocrine, Stockholm, Sweden) at a flow rate of $50 \mathrm{ml} / \mathrm{s}$ according to ERS/ATS guidelines. ${ }^{18}$

Baseline spirometry was performed using a portable spirometer (Compact Vitalograph Ltd, Buckingham, UK) in accordance with ATS/ERS guidelines. ${ }^{19}$ A dose of $1000 \mu \mathrm{g}$ salbutamol (10 puffs) was administered by a metered dose inhaler through a spacer and spirometry repeated after $15 \mathrm{~min}$ and bronchodilator reversibility calculated. Hypertonic saline used for sputum induction can cause bronchoconstriction, but it has been shown to be safe in children with severe asthma if pretreated with $1000 \mu \mathrm{g}$ salbutamol. ${ }^{20}$

Sputum induction was performed using a DeVilbiss 2000 Ultrasonic nebuliser (Somerset, Pennsylvania, USA) and inhalation of hypertonic (3.5\%) saline as previously described. ${ }^{20}$ Subjects with a post-bronchodilator forced expiratory volume in $1 \mathrm{~s}\left(\mathrm{FEV}_{1}\right)<65 \%$ predicted or previous adverse events with hypertonic saline underwent induction with normal $(0.9 \%)$ saline.

Selected sputum plugs were processed as previously reported. ${ }^{21}$ Differential cell counts were determined by assessment of 400 non-squamous cells on Reastain Quick-Diff-stained cytospins.

Table 1 Algorithm for treatment changes in the symptom and inflammatory management groups

\begin{tabular}{|c|c|c|c|}
\hline & $\begin{array}{l}\text { Increase } \\
\text { treatment }\end{array}$ & $\begin{array}{l}\text { No change } \\
\text { in treatment }\end{array}$ & $\begin{array}{l}\text { Decrease } \\
\text { treatment }\end{array}$ \\
\hline \multicolumn{4}{|l|}{ Symptom management group } \\
\hline \multirow{2}{*}{$\begin{array}{l}\text { Number of major exacerbations } \\
\text { (courses of OCS) }\end{array}$} & $>1$ & $\leq 1$ & $\leq 1$ \\
\hline & $\mathrm{OR}$ & AND & AND \\
\hline SABA usage (times per week) & $>5$ & $3-5$ & $<3$ \\
\hline \multicolumn{4}{|l|}{ Inflammatory management group } \\
\hline \multirow[t]{2}{*}{ Sputum eosinophils, \% } & $>2.5$ & $0.1-2.5$ & $<0.1$ \\
\hline & $\mathrm{OR}$ & $\mathrm{OR}$ & $\mathrm{OR}$ \\
\hline $\begin{array}{l}\mathrm{FE}_{\mathrm{NO}}, \mathrm{ppb} \text { (if no sputum sample } \\
\text { available) }\end{array}$ & $>30$ & $22-30$ & $<22$ \\
\hline
\end{tabular}


At each study visit, data on asthma control were collected including daytime symptoms, nocturnal symptoms, exerciseinduced symptoms, SABA use in the 2 weeks preceding the study visit and control in a typical week over the previous 3 months. The number of exacerbations since the previous study visit was recorded. Asthma exacerbations were managed in accordance with BTS guidelines and subjects were not routinely seen by a member of the study team during an exacerbation. Adherence was assessed using prescription records.

\section{Definition of minor and major exacerbations}

A minor exacerbation was defined as any deterioration in asthma control which necessitated the use of bronchodilators $>5$ times per week (excluding routine use such as before exercise). A major exacerbation was defined as deterioration in asthma control requiring a course of high-dose OCS ( $\geq 20 \mathrm{mg}$ / day) for at least 2 days. Exacerbations were based on self-reports and verified using GP prescription records and hospital admission data. As children were not routinely seen by the study team during an exacerbation, we felt that the need for OCS had to be determined by the clinician who saw the child in exacerbation and it was not ethical to try to use preset criteria.

\section{Statistical analysis}

The primary analysis was based on the rate of major exacerbations and asthma control as assessed by symptom-free days and SABA use. The method of weighted means was used to compare rates of exacerbations in the symptom management and inflammatory management groups (total exacerbations in each group divided by the total follow-up time for that group). ${ }^{22}$ The $p$ value was calculated by assuming a Poisson distribution for the number of exacerbations. The variability in exacerbation rates between subjects was accounted for by using an overdispersion parameter. The secondary outcome was the daily dose of ICS prescribed over the course of the study. Comparisons between the two management groups for the ICS dose prescribed at the start and end of the study were made using the Mann-Whitney test. Longitudinal analysis of variables such as ICS dose, measured multiple times over the course of the study, was carried out using multilevel mixed models. Fixed effect models were used to assess the effect of the management strategy on each variable and a correction was also made to adjust for baseline values for each parameter. Comparison of proportions between groups was performed using the Pearson $\chi^{2}$ test. Subjects were analysed on an intention-to-treat basis. All analyses were carried out using SPSS software V.16 except the longitudinal analysis which was carried out using STATA software V.10. The significance level for all tests was set at $p<0.05$. A power calculation was not possible as data were not available for the annual exacerbation rate of this group of patients. As this was the first study of its kind to be carried out in children, the sample size was based on a previous adult study. ${ }^{14}$

\section{RESULTS}

Fifty-five subjects were recruited, of which 49 (24 in the symptom management group) fulfilled the criteria for study completion (attendance of at least two study visits and a followup visit within the study period). One subject was withdrawn from the study because of poor asthma control. The trial profile is shown in figure 2. A total of 204 study visits were completed. The two groups were well matched at baseline for demographic and clinical characteristics (table 2).

Sputum induction was successful on 174 (85\%) occasions; 152 of these samples were evaluable and a sputum differential cell count obtained. Fifty-one subjects (93\%) produced at least one evaluable sputum sample over the course of the study. $\mathrm{FE}_{\mathrm{NO}}$ was used to determine management on 27 occasions. Sputum induction was well tolerated with only minor side effects reported. On $92(45 \%)$ occasions (46 occasions in each group) the decision according to the inflammatory and symptom management algorithms was the same (discordant:concordant ratio 1.2 ). ${ }^{23}$

The inflammatory management group had fewer total and major cumulative exacerbations over the course of the study than the symptom management group (100 vs 132 and 42 vs 74, respectively). The weighted mean rates of total, major and minor exacerbations were non-significantly lower in the inflammatory group than in the symptom group (3.6 vs 4.8, incident rate ratio (IRR) $0.75,95 \%$ CI 0.54 to $1.04, p=0.082$ for total exacerbations; 1.9 vs 2.7 , IRR $0.73,95 \%$ CI 0.42 to 1.28 , $p=0.274$ for major exacerbations; and 1.7 vs 2.1 , IRR $0.79,95 \%$ CI 0.47 to $1.27, \mathrm{p}=0.311$ for minor exacerbations).

The proportion of subjects having 0,1 or $\geq 2$ exacerbations over the duration of the study was not significantly different between the groups (figure 3). There was no significant difference between the groups in total number of hospital admissions (13 for the inflammatory group vs 10 for the symptom group).

In a post hoc analysis, significantly fewer subjects in the inflammatory management group had an exacerbation (total and major) within 14 days of the study visit and this significant difference persisted until 28 days after the study visit for total exacerbations. No differences existed by 90 days (figure 4).

The inflammatory management group had 0.4 more symptom-free days per week $(p=0.32)$ and 0.5 fewer disturbed nights $(p=0.10)$ per week over the course of the study; however, these results are not statistically significant (figure E1 in online supplement). The proportion of subjects in the inflammatory group using SABA > 5 times in a week fell from $56 \%$ at visit 1 to $50 \%$ at the final follow-up, whereas the proportion in the

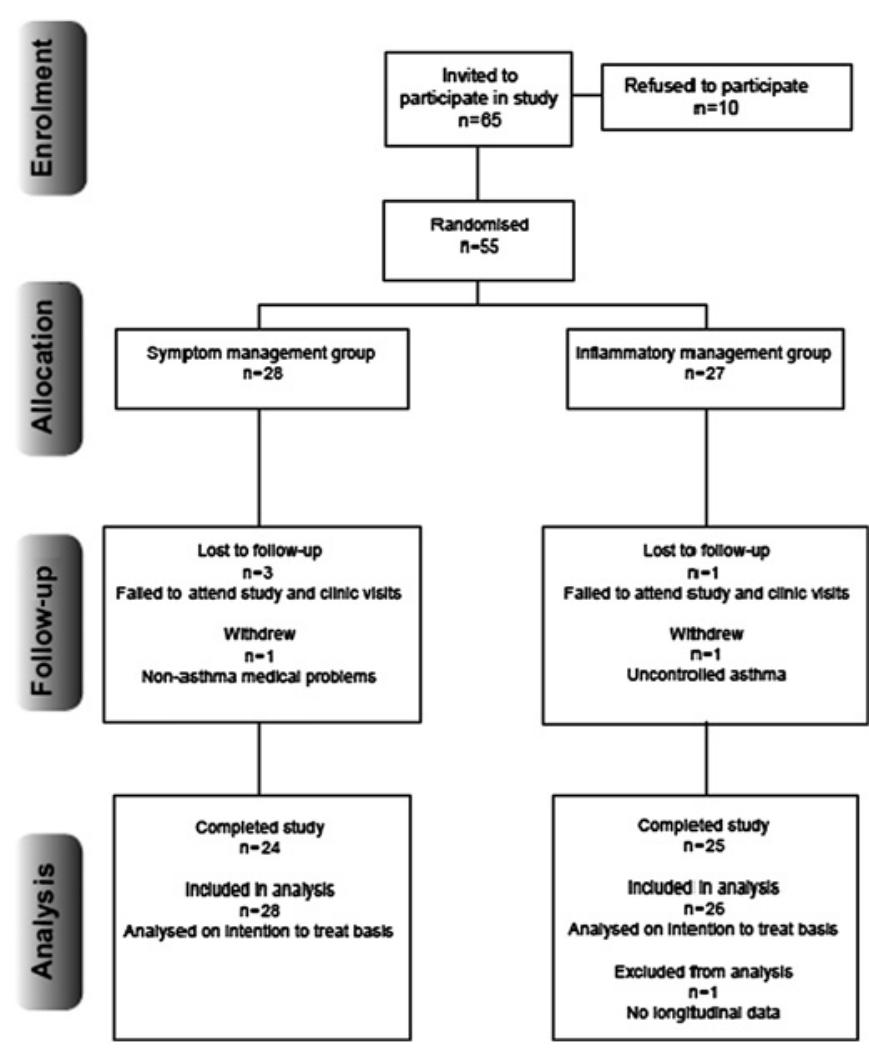

Figure 2 Trial profile. 
Table 2 Subject demographics at baseline

\begin{tabular}{|c|c|c|}
\hline & $\begin{array}{l}\text { Symptom } \\
\text { management } \\
\text { group }(n=28)\end{array}$ & $\begin{array}{l}\text { Inflammatory } \\
\text { management } \\
\text { group }(n=27)\end{array}$ \\
\hline \multicolumn{3}{|l|}{ Demographics } \\
\hline Male & $13(46 \%)$ & $16(59 \%)$ \\
\hline Age (years) & $12.6(10.2-14.7)$ & $13.4(11.1-15.8$ \\
\hline Atopic & $23(82 \%)$ & $23(85 \%)$ \\
\hline \multicolumn{3}{|l|}{ Clinical characteristics } \\
\hline $\begin{array}{l}\text { Duration of asthma symptoms } \\
\text { (years) }\end{array}$ & $11.2(8.2-13.7)$ & $11.2(9.3-14.6)$ \\
\hline Age ICS started (years) & $3.0(1.0-4.0)$ & $3.0(2.0-5.0)$ \\
\hline Previous admission to PICU ever & $6(21 \%)$ & $5(19 \%)$ \\
\hline Daily dose of FP $(\mu \mathrm{g})$ & $625(500-1000)$ & $500(500-1000)$ \\
\hline Maintenance OCS & $4(14 \%)$ & $4(15 \%)$ \\
\hline $\begin{array}{l}\text { Major exacerbations in } \\
\text { previous year }\end{array}$ & $3.5(1-6)$ & $2.0(0-6)$ \\
\hline $\begin{array}{l}\geq 1 \text { major exacerbation in } \\
\text { previous year }\end{array}$ & $23(82 \%)$ & $20(74 \%)$ \\
\hline Sputum eosinophil count (\%) & $1.8(0-5.6)$ & $5.3(0.3-17.5)$ \\
\hline Eosinophil count $>2.5 \%$ & 7 (39\%) & $9(53 \%)$ \\
\hline Sputum neutrophil count (\%) & $18.3(10.9-24.9)$ & $31.3(7.5-74.0)$ \\
\hline $\mathrm{FE}_{\mathrm{No}}(\mathrm{ppb})$ & $35.5(18.8-59.8)$ & $23.5(13.5-59.9)$ \\
\hline $\mathrm{FE}_{\mathrm{NO}}>30 \mathrm{ppb}$ & $16(57 \%)$ & $12(44 \%)$ \\
\hline z score $\mathrm{FEV}_{1}$ & $-1.2(1.2)$ & $-1.2(1.2)$ \\
\hline \multicolumn{3}{|l|}{ Asthma control at baseline* } \\
\hline Symptom-free days per week & $5(4-6)$ & $4(0-5.5)$ \\
\hline Nights per week of sleep disruption & $1(0-2)$ & $0.5(0-4)$ \\
\hline SABA use $>5$ times per week & $15(54 \%)$ & $15(56 \%)$ \\
\hline Exercise-induced symptoms & $19(76 \%)$ & $17(71 \%)$ \\
\hline
\end{tabular}

Data are expressed as median (IOR) or number (\%), except FEV ${ }_{1}$ which is expressed as mean (SD).

*Patient recall in the 2 weeks prior to enrolment.

$\mathrm{FE}_{\mathrm{NO}}$, exhaled nitric oxide; $\mathrm{FEV}_{1}$, forced expiratory volume in $1 \mathrm{~s}$; $\mathrm{FP}$, fluticasone propionate; ICS, inhaled corticosteroids; OCS, oral corticosteroids; PICU, paediatric intensive care unit; SABA, short-acting $\beta$ agonist.

symptom group increased from $54 \%$ to $67 \%$. In neither group were these changes significant.

In each of the groups the median daily dose of ICS at the end of the study was non-significantly higher than at the start. Over the course of the study the inflammatory group were prescribed a non-significantly lower ICS dose by $43 \mu \mathrm{g}$ per day compared with the symptom group ( $\mathrm{p}=0.40$; figure $\mathrm{E} 2$ in online supplement).

Sputum eosinophils in the inflammatory group fell from a median of $5.3 \%$ at visit 1 to $1.5 \%$ at visit 4 , whereas there was a slight increase in sputum eosinophil count in the symptom group from $1.8 \%$ to $2.3 \%$. For neither group were these changes significant. Over the duration of the study the sputum eosinophil count was non-significantly higher in the inflammatory group by $2.2 \%$ ( $p=0.48$; figure 5 ). In total, $46 \%$ of sputum

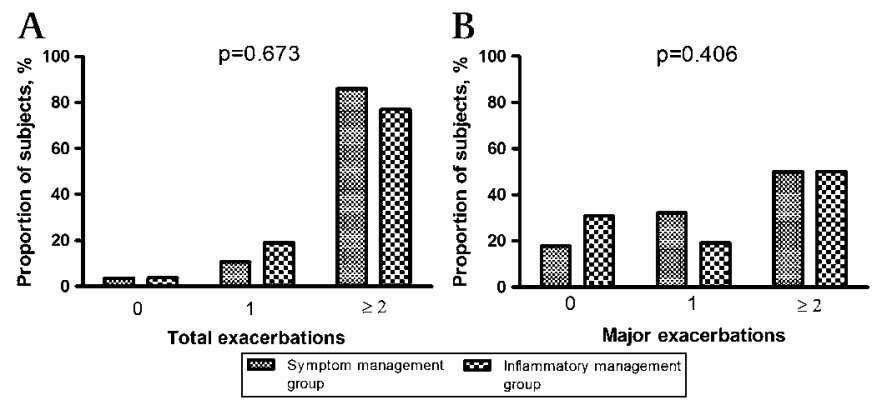

Figure 3 Frequency distribution of subjects in each group having 0, 1 and $\geq 2$ exacerbations over the duration of the study. (A) Total exacerbations. (B) Major exacerbations.

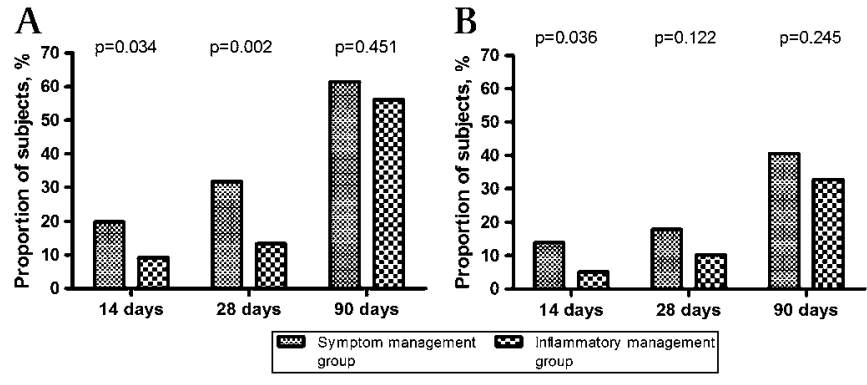

Figure 4 Proportion of subjects having an exacerbation within 14, 28 and 90 days of the study visit. (A) Total exacerbations. (B) Major exacerbations.

samples had an eosinophil count of $\leq 2.5 \%$ ( $49 \%$ in the symptom group and $42 \%$ in the inflammatory group). This did not vary significantly between the groups, nor did it change significantly for either group over the course of the study. The $\mathrm{FE}_{\mathrm{NO}}$ levels did not change significantly over the study period (figure E3 in online supplement).

Both groups showed a significant improvement in $\mathrm{FEV}_{1} \mathrm{z}$ score from the start to the end of the study. There was no significant difference between the groups. The mean (SE) difference was 0.51 (0.37) for the symptom group and 0.49 (0.34) for the inflammatory group (figure E4 in online supplement). Bronchodilator reversibility did not change significantly over the duration of the study for either group.

Post hoc subgroup analysis showed that boys in the inflammatory group had a significantly lower rate of major exacerbations than boys in the symptom management group (median (IOR) $0.45(0-1.3)$ vs. $2.8(0-6.1), \mathrm{p}=0.018)$. Subgroup analyses according to other baseline characteristics including sex, age (12 years), atopy and sputum eosinophil count (normal or abnormal) were not associated with differences between the groups.

\section{DISCUSSION}

This is the first study to report the outcome of a randomised controlled trial incorporating the measure and control of sputum eosinophils into the management algorithm for children with severe asthma. Although there was a reduction in the overall rate of total and major exacerbations in the inflammatory management group, this was not statistically significant and thus these findings are different from those reported for previous studies in adult asthma populations. ${ }^{13-15}$ Nonetheless, a number of interesting findings emerged to indicate that there may be some effect of an inflammation-based management strategy.

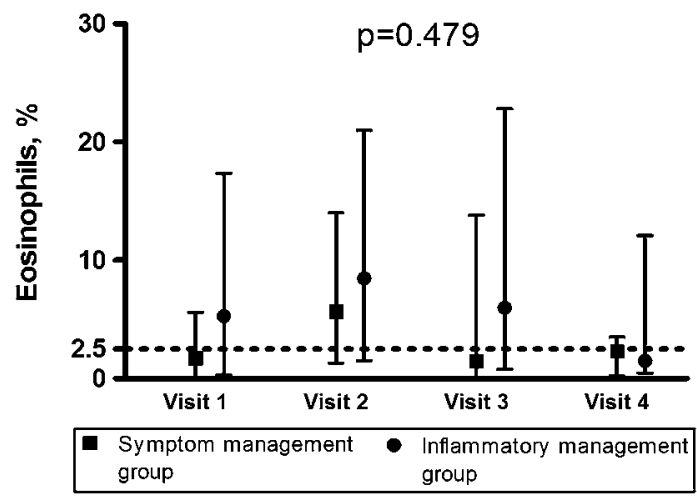

Figure 5 Sputum eosinophil counts (\%) for each study visit. Median and IQR are shown. The $\mathrm{p}$ value is derived from the longitudinal time series analysis. The dotted line denotes the $2.5 \%$ level of sputum eosinophils. 
Although the primary outcome was negative, it cannot necessarily be inferred that sputum eosinophils were the wrong target but rather that the strategy to control them was not successful. It is striking that sputum eosinophils were controlled no better in the inflammatory management group than in the symptom group. The most plausible explanation for the failure to control eosinophilic inflammation adequately lies in the treatment algorithm. The strategy of increasing doses of ICS was based on the hypothesis that there would be a continued anti-inflammatory effect at higher than conventional doses of ICS. The plateau of the dose-response curve for ICS is reported to be $200-500 \mu \mathrm{g} /$ day FP equivalent. ${ }^{24-27}$ There is some evidence that increasing to very high doses of FP (2000 $\mu \mathrm{g} /$ day $)$ or budesonide $(1600 \mu \mathrm{g} /$ day) may afford some clinical benefit in very severe asthma. ${ }^{24}{ }^{25}$ However, this evidence is largely derived from adult studies and there is a lack of data in children with severe asthma on the inflammatory response to high-dose ICS. Allowing a cap of $1000 \mu \mathrm{g} /$ day FP in some children may have diminished the possibility of seeing an effect from very high doses of ICS. A more effective strategy may have been to have had a fixed ICS threshold for changing to OCS rather than leaving this decision to the discretion of the respiratory paediatrician in charge of the child's asthma management. A major concern in children with asthma is the side effects of corticosteroids. It is difficult to know whether this seemingly more aggressive strategy would have been acceptable to the children and their parents and a balance must always be struck between effectively controlling asthma symptoms and exacerbations and the risk of treatment side effects. However, it clearly needs to be the subject of a further study and the reluctance to step up to regular OCS and to allow a $1000 \mu \mathrm{g} /$ day FP cap are acknowledged weaknesses of the algorithm used in this study. This issue is further compounded by problems with adherence. Prescription uptake while enrolled in the study was $<80 \%$ in over half the subjects for whom prescription records were available, which is similar to that previously reported for adults and children with difficult asthma. ${ }^{28} 29$ It is likely that both management strategies would have been affected by poor adherence and alternative treatment algorithms may have been no more effective without improved adherence. It would have been useful to have obtained more accurate data on adherence using an electronic recording device $^{30}$ and improved adherence may have been achieved with closer monitoring. ${ }^{31}$

Sputum eosinophils only started to fall in the inflammatory management group in the latter part of the study. The duration of the study in two other adult sputum eosinophil-based management studies was 18-24 months. ${ }^{13}{ }^{15}$ A greater length of follow-up in this study would have allowed an opportunity to see if this reduction in sputum eosinophils was sustained and whether this had an effect on exacerbations. It is also noteworthy that the number experiencing a major exacerbation within 14 days of the study visit was significantly less in the inflammatory group and there was also a significant decrease for all exacerbations up to 28 days after the study visit. It is possible that an effect was missed in this study because the measurements of inflammation were not carried out sufficiently frequently. In the study carried out in adults by Green et al, subjects were seen every month for the first 4 months and then 2-monthly for the remaining 8 months. ${ }^{14}$ A greater frequency of measurements may have led to more precise tailoring of treatment and tighter control of eosinophils.

It is possible that the results would have been different if a larger number of children could have been recruited. In the study carried out by Green et al on which the power calculation for this study was based, 68 patients completed follow-up. ${ }^{14}$ However, there were a greater number of exacerbations requiring high-dose OCS (the primary outcome measure) in our study, despite the lower subject numbers. However, a larger study population would have been preferable. This is the first study of this kind in children with severe asthma and the results can be used to inform and power future studies.

The success rate for obtaining an evaluable sputum sample was comparable to that reported in other paediatric studies. ${ }^{16}$ When a sputum eosinophil count was not available, $\mathrm{FE}_{\mathrm{NO}}$ was used instead. Previous studies in children which have incorporated $\mathrm{FE}_{\mathrm{NO}}$ into management strategies ${ }^{31-33}$ have not shown a reduction in exacerbations compared with a symptom-based management strategy. Using $\mathrm{FE}_{\mathrm{NO}}$ as a surrogate marker for sputum eosinophils may have reduced the possibility of demonstrating a significant effect in this study, although a subgroup analysis of those for whom all treatment decisions were based on sputum eosinophils (and $\mathrm{FE}_{\mathrm{NO}}$ was not used at all) did not show significant differences in outcomes. Furthermore, at present there is not another reliable easily measurable non-invasive biomarker for eosinophilic inflammation.

Some of the limitations discussed, particularly those related to treatment options and frequency of visits, are reflective of clinical paediatric practice and these results should be interpreted in this context. In view of these constraints, it would be wrong to draw the conclusion that sputum eosinophils are not a marker of steroid-responsive disease in paediatric severe asthma and should not be used as a treatment target; rather, the way in which we aim to control inflammation needs to be refined. The results of the subgroup analyses suggest that certain groups may benefit from such a strategy. Further work is needed to verify this finding and identify subgroups of children with severe asthma for whom an inflammation-based management plan may be of benefit and how best such a strategy should be implemented. Encouragingly, sputum induction was generally acceptable to the children, well-tolerated and increasingly successful at each study visit. However, monthly sputum induction is unlikely to be a practical clinical strategy in most children, suggesting the need for a better biomarker.

In conclusion, it was not possible to show a significant benefit of measuring sputum eosinophils at 3-monthly intervals in reallife practice in an unselected group of children with very severe asthma. The results reported here may be used to inform future work and power calculations. We suggest that children enrolled in the study should preferable be seen monthly, and also that the FP dosage should be capped, probably at $1000 \mu \mathrm{g} /$ day, as part of the protocol and oral steroids added routinely above that level.

Acknowledgements We would like to thank all the children and their parents who participated in the study and the staff in the Paediatric Respiratory Department at the Royal Brompton Hospital who supported this study, in particular Drs lan BalfourLynn, Mark Rosenthal and Claire Hogg who allowed their patients to participate. We are grateful to Winston Banya, RBH statistician, for statistical advice and for performing the STATA analyses.

Funding The study was funded by a grant from the British Lung Foundation.

\section{Competing interests None.}

Ethics approval This study was conducted with the approval of the Royal Brompton Hospital ethics committee.

Contributors $A B$ and NW were the principal investigators, obtained funding for the study, participated in the study design and writing of the report. LF carried out the study visits, data management, data analyses, interpretation of results and writing of the report. NR carried out all the sputum cell counts, participated in idea formation and the writing of the report. All authors approved the final version.

Provenance and peer review Not commissioned; externally peer reviewed. 


\section{REFERENCES}

1. GINA. Global Initiative for Asthma: Global Strategy for Asthma Management and Prevention 2008. http://www. ginasthma.org (accessed Jul 2009).

2. National Heart, Lung and Blood Institute. National Asthma Education and Prevention Program. Expert Panel Report 3: Guidelines for the Diagnosis and Management of Asthma 2007. http://www.nhlbi.nih.gov/guidelines/asthma/asthgdln. htm (accessed Jul 2009).

3. British Thoracic Society/Scottish Intercollegiate Guidelines Network. British guideline on the management of asthma. Thorax 2008;63(Suppl 4):iv1-121.

4. Bacharier LB, Strunk RC, Mauger D, et al. Classifying asthma severity in children: mismatch between symptoms, medication use, and lung function. Am J Respir Crit Care Med 2004;170:426-32.

5. Sullivan SD, Wenzel SE, Bresnahan BW, et al. Association of control and risk of severe asthma-related events in severe or difficult-to-treat asthma patients. Allergy 2007:62:655-60.

6. Todd GR, Acerini CL, Ross-Russell R, et al. Survey of adrenal crisis associated with inhaled corticosteroids in the United Kingdom. Arch Dis Child 2002;87:457-61.

7. Martinez FD. Safety of long-acting beta-agonists: an urgent need to clear the air. N Engl J Med 2005:353:2637-9.

8. Wilson NM, Bridge P, Spanevello A, et al. Induced sputum in children: feasibility, repeatability, and relation of findings to asthma severity. Thorax 2000;55:768-74.

9. Zacharasiewicz A, Wilson N, Lex C, et al. Clinical use of noninvasive measurements of airway inflammation in steroid reduction in children. Am $\mathrm{J}$ Respir Crit Care Med 2005;171:1077-82.

10. Bacci E, Cianchetti S, Bartoli M, et al. Low sputum eosinophils predict the lack of response to beclomethasone in symptomatic asthmatic patients. Chest 2006;129:565-72.

11. Green RH, Brightling CE, Woltmann G, et al. Analysis of induced sputum in adults with asthma: identification of subgroup with isolated sputum neutrophilia and poor response to inhaled corticosteroids. Thorax 2002:57:875-9.

12. Little SA, Chalmers GW, Macleod KJ, et al. Non-invasive markers of airway inflammation as predictors of oral steroid responsiveness in asthma. Thorax 2000;55:232-4.

13. Chlumsky J, Striz I, Terl M, et al. Strategy aimed at reduction of sputum eosinophils decreases exacerbation rate in patients with asthma. J Int Med Res 2006;34:129-39.

14. Green RH, Brightling CE, McKenna S, et al. Asthma exacerbations and sputum eosinophil counts: a randomised controlled trial. Lancet 2002;360:1715-21.

15. Jayaram L, Pizzichini MM, Cook RJ, et al. Determining asthma treatment by monitoring sputum cell counts: effect on exacerbations. Eur Respir $J$ 2006;27:483-94.

16. Gibson PG, Grootendor DC, Henry RL, et al. Sputum induction in children. Eur Respir J Supp/ 2002;37:44s-6s.

17. Kips JC, Inman MD, Jayaram L, et al. The use of induced sputum in clinical trials. Eur Respir J Supp/ 2002;37:47s-50s.
18. American Thoracic Society/European Respiratory Society. ATS/ERS recommendations for standardized procedures for the online and offline measurement of exhaled lower respiratory nitric oxide and nasal nitric oxide, 2005 Am J Respir Crit Care Med 2005:171:912-30.

19. Miller MR, Hankinson J, Brusasco V, et al. Standardisation of spirometry. Eur Respir J 2005;26:319-38

20. Lex C, Payne DN, Zacharasiewicz A, et al. Sputum induction in children with difficult asthma: safety, feasibility, and inflammatory cell pattern. Pediatr Pulmonol 2005:39:318-24.

21. Pizzichini E, Pizzichini MM, Efthimiadis A, et al. Indices of airway inflammation in induced sputum: reproducibility and validity of cell and fluid-phase measurements. Am J Respir Crit Care Med 1996;154:308-17.

22. Suissa S. Statistical treatment of exacerbations in therapeutic trials of chronic obstructive pulmonary disease. Am J Respir Crit Care Med 2006;173:842-6.

23. Gibson PG. Using fractional exhaled nitric oxide to guide asthma therapy: design and methodological issues for ASthma TReatment ALgorithm studies. Clin Exp Allergy 2009:39:478-90.

24. Adams N, Bestall J, Jones PW. Budesonide at different doses for chronic asthma Cochrane Database Syst Rev 2001;(4):CD003271.

25. Adams NP, Bestall JC, Jones PW, et al. Inhaled fluticasone at different doses for chronic asthma in adults and children. Cochrane Database Syst Rev 2005;(3): CD003534.

26. Adams NP, Jones PW. The dose-response characteristics of inhaled corticosteroids when used to treat asthma: an overview of Cochrane systematic reviews. Respir Med 2006;100:1297-306

27. Masoli M, Weatherall M, Holt S, et al. Clinical dose-response relationship of fluticasone propionate in adults with asthma. Thorax 2004;59:16-20.

28. Bracken $\mathbf{M}$, Fleming $L$, Hall $P$, et al. The importance of nurse-led home visits in the assessment of children with problematic asthma. Arch Dis Child 2009;94:780-4.

29. Gamble J, Stevenson M, McClean E, et al. The prevalence of non-adherence in difficult asthma. Am J Respir Crit Care Med 2009;180:817-22.

30. Bender B, Wamboldt FS, O'Connor SL, et al. Measurement of children's asthma medication adherence by self report, mother report, canister weight, and Doser CT. Ann Allergy Asthma Immunol 2000;85:416-21.

31. De Jongste JC, Carraro $S$, Hop WC, et al. Daily telemonitoring of exhaled nitric oxide and symptoms in the treatment of childhood asthma. Am J Respir Crit Care Med 2009;179:93-7

32. Pijnenburg MW, Bakker EM, Hop WC, et al. Titrating steroids on exhaled nitric oxide in children with asthma: a randomized controlled trial. Am J Respir Crit Care Med 2005;172:831-6.

33. Szefler SJ, Mitchell H, Sorkness CA, et al. Management of asthma based on exhaled nitric oxide in addition to guideline-based treatment for inner-city adolescents and young adults: a randomised controlled trial. Lancet 2008;372:1065-72.

\section{Journal club}

\section{Statins may decrease all cause mortality in pneumonia}

This cohort study compared all cause mortality within 6 months after contracting pneumonia in patients who had been taking a statin prior to developing pneumonia against those who had not. Data were sourced from The Health Improvement Network database and validated for pharmacoepidemiological research; propensity scoring was used for comparative analysis of patients in the two subgroups. A total of 129288 patients who had received a statin were matched with 600241 patients who had not. Following exclusions and restrictions, 942 statin users and 3615 non-users were included in the analysis. Of these, 204 statin users and 1264 non-users died within 6 months of the date of diagnosis of pneumonia. The fully adjusted rate ratio for mortality between statin users and non-users was 0.67 ( $95 \% \mathrm{CI} 0.49$ to 0.87 ). An estimation of the number needed to treat to prevent one death within 6 months of an episode of pneumonia was 15 .

The results of this study show that the risk of dying within 6 months of pneumonia is lower among patients established on statin treatment when the pneumonia occurred. The authors support a case for randomised trials of statins in patients with pneumonia to determine whether a short period of statin treatment could reduce mortality.

Douglas I, Evans S, Smeeth L. Effect of statin treatment on short term mortality after pneumonia episode: cohort study. BMJ 2011;342:d1642. doi:10.1136/bmi.d1642.

\section{Hugo Gemal}

Correspondence to Hugo Gemal, University College Hospital, London, UK; hgemal@nhs.net

Published Online First 23 August 2011

Thorax 2012;67:198. doi:10.1136/thoraxjnl-2011-200826 